Article

\title{
Effects of Fusarium solani and $F$. oxysporum Infection on the Metabolism of Ginsenosides in American Ginseng Roots
}

\author{
Xiaolin Jiao ${ }^{1, \dagger}$, Xiaohong Lu ${ }^{1, \dagger}$, Amanda Juan Chen ${ }^{1}$, Yi Luo ${ }^{1}$, Jianjun J. Hao ${ }^{2}$ \\ and Weiwei Gao $1, *$
}

1 Institute of Medicinal Plant Development, Chinese Academy of Medical Sciences and Peking Union Medical College, Beijing 100193, China; E-Mails: jiao_1110@163.com (X.J.); luchauluchau@gmail.com (X.L.); chenj@implad.ac.cn (A.J.C.); impladroy@gmail.com (Y.L.)

2 School of Food and Agriculture, University of Maine, Orono, ME 04469, USA;

E-Mail: jianjun.hao1@maine.edu

$\dagger$ These authors contributed equally to this work.

* Author to whom correspondence should be addressed; E-Mail: wwgao411@sina.com; Tel.: +86-10-5783-3423.

Academic Editor: Derek J. McPhee

Received: 7 April 2015 / Accepted: 3 June 2015 / Published: 8 June 2015 / Corrected: 7 June 2022

\begin{abstract}
American ginseng (Panax quinquefolius L.) is a highly valuable herb widely used for medicinal treatments. Its pharmacologically important compounds are the ginsenosides, which are secondary metabolites in American ginseng root. The concentrations of ginsenoside in roots can be changed by fungal infection, but it is unclear what specific root tissues are impacted and whether the change is systemic. In this study, American ginseng roots were inoculated with two fungal pathogens (Fusarium solani or F. oxysporum) and the levels of six ginsenosides $\left(\mathrm{Rb}_{1}, \mathrm{Rb}_{2}, \mathrm{Rc}, \mathrm{Rd}, \mathrm{Re}\right.$, and $\left.\mathrm{Rg}_{1}\right)$ were then measured in the phloem and xylem around the discolored lesions and adjacent healthy areas of the root. Results indicated that the growth of Fusarium spp. was strictly limited to phloem, and correspondingly the ginsenoside concentration was only altered in this infected phloem. The concentration of $\mathrm{Rg}_{1}, \mathrm{Rd}$, and $\mathrm{Rc}$ significantly changed in phloem tissues where $F$. solani was inoculated, while only $\mathrm{Rg}_{1}$ and $\mathrm{Rd}$ changed significantly after $F$. oxysporum inoculation. However, no changes of any ginsenoside occurred in either xylem or phloem tissue adjacent to the inoculation point. In addition, when two Fusarium spp. were grown on ginsenoside-amended Czapek medium, the majority of ginsenosides were depleted. Therefore, pathogenic Fusarium spp. may reduce ginsenoside levels by consuming them.
\end{abstract}


Keywords: Panax quinquefolius; root pathogen; chemical response; biodegradation

\section{Introduction}

American ginseng (Panax quinquefolius L.) is mainly cultivated in the United States, Canada, and China [1]. It is a highly valuable perennial herb and has been widely used in Asia for hundreds of years as a medicinal and dietary supplement [1]. American ginseng produces a group of dammarane-type saponins known as ginsenosides. Some of the common ginsenosides such $\mathrm{as} \mathrm{Rb}_{1}, \mathrm{R} \mathrm{b}_{2}, \mathrm{Rc}, \mathrm{Rd}, \mathrm{Re}$, and $\mathrm{Rg}_{1}$ are active compounds responsible for the multiple pharmacological functions attributed to the plant [2,3], including anti-aging [4,5], anti-obesity [4], anti-hyperglycemic [4], and anti-infection activities [6,7], promotion for sperm motility and progression [8], and antimicrobial activities against bacteria [9].

Ginseng roots growing in the field are susceptible to several soil-borne diseases. These diseases are primarily caused by fungal pathogens, including several species of Fusarium [10-12], (causing root rot or rusty root), Rhexocercosporidium panacis (causing rusty root) [13], Cylindrocarpon destructans (causing root rot) [14,15], Phytophthora cactorum (causing Phytophthora root rot) [14,16], and Pythium species (causing damping-off) [15]. Among these pathogens, Fusarium solani and F. oxysporum are highly aggressive fungi causing American ginseng root rot in the Beijing ginseng producing region of China [10]. Typical early stage symptoms of this disease are reddish-brown to orange-brown discolored areas on the root surface. As the disease develops, symptoms include dry rot in both exterior and interior root tissues, and loss of fibrous roots. The infection of the root tissues may be associated with changes in the ginsenoside contents [17].

Saponins play an important role in the chemical defenses of plants against pathogen infections [18]. Some soil-borne pathogens are inhibited by ginsenosides [19,20], but some of these pathogens can alter the ginsenoside contents in return [21]. Gao et al. [17] have demonstrated that the quantity of ginsenoside Re was significantly reduced in the phloem, but increased in the xylem of American ginseng roots severely infected with root rot. A significant change has been reported in the level of ginsenoside $\mathrm{Rb}_{1}$ in infected roots five days post-inoculation [21]. However, the changes in the ginsenosides profile at stages of infection longer than 5 days are not fully understood, as a longer period of infection by pathogen is considered to alter the chemical composition and medicinal value of American ginseng roots to a greater extent [17].

A previous study [12] showed that the concentrations of ginsenoside $\mathrm{Rg}_{1}, \mathrm{Rd}, \mathrm{R} \mathrm{b}_{1}, \mathrm{Re}, \mathrm{Rc}$, and $\mathrm{Rb}_{2}$ are reduced in infected epidermal and cortical tissues of American ginseng roots with rusty root symptoms. This study was conducted using ginseng roots collected from ginseng fields. As in the field a major pathogen is often accompanied with or followed by multiple other microorganisms, either pathogenic to ginseng roots or not [11,14], it is difficult to conclude that the ginsenoside reduction is due to any specific pathogen. This makes identifying the specific fungi that directly cause the ginsenoside alteration difficult, as other microorganisms can also change the concentrations of antimicrobial compounds in plants [22,23]. In addition, it is not exactly clear in which part of root tissue these 
compounds can be altered by fungal infection. Thus, laboratory assays using pure cultures of target organisms (pathogens) under a controlled environment are necessary.

We have previously found that $\mathrm{Rb}_{1}$ was rapidly induced within three to five days of inoculation by Fusarium solani and F. oxysporum, but the contents of $\mathrm{Re}$ or $\mathrm{Rg}_{1}$ were not significantly altered [21]. This suggests that $R b_{1}$, instead of $R e$ or $R g_{1}$, is likely the active compound that inhibits conidial germination of Fusarium spp. [21]. The six ginsenosides $\mathrm{Rb}_{1}, \mathrm{Rb}_{2}, \mathrm{Rc}, \mathrm{Rd}, \mathrm{Re}$, and $\mathrm{Rg}_{1}$ are similar in structure - they are all dammarane-type triterpenoid saponins, and have a common biosynthesis pathway - but whether their responses to pathogen infection are similar is unclear. Such a speculation is comparable to the case of other phytoanticipins/phytoalexins that share the same type of chemical structure but usually differ in function [24,25].

In China, American ginseng roots with visible necrosis are usually not discarded because of the high economic value of the uninfected tissue parts. Although the diseased tissues are eventually removed before consumption, it is not clear whether the ginsenoside content is affected in the rest tissues adjacent to the diseased lesions. Thus we were interested in how and where the contents of ginsenoside change upon Fusarium infection. The objectives of this study were to: (i) determine the effect of Fusarium on ginsenoside contents of American ginseng root during an extended period of infection; (ii) determine whether the alteration of ginsenoside is directly caused by metabolism of Fusarium spp.; and (iii) if Fusarium is the sole reason for ginsenoside alteration.

\section{Results and Discussion}

\subsection{Molecular Detection of Fusarium spp. in American Ginseng Roots}

Seven days after inoculation with F. solani (strain F19), cream sparse mycelia were present on the root surface, originating from the inoculation point. The center of disease lesions appeared reddish brown. In the case of $F$. oxysporum (strain $\mathrm{C} 1$ ), the entire infected root parts were covered with flourishing floccose white mycelia. In order to distinguish the late stage effects from the early stage ones, we defined the late stage as when visible disease symptoms and thick plaque were observed on ginseng roots after fungal infection. These phenotypes usually occurred seven days after inoculation, and were not clearly visible in the early stage of infection, as previously described [21].

The presence of fungi was only detected using polymerase chain reaction (PCR) in the phloem tissue directly under Fusarium mycelial plug (III-PF), suggesting that phloem cells of American ginseng root were infected upon contacting with fungal hyphae whereas the xylem cells were not affected. Interestingly, seven days after inoculation, the spread of fungi was restricted to the area with direct contact of fungal inoculums, not adjacent tissues in the phloem (III-P), despite the appearance of vigorous growth of fungal mycelia (Figure 1).

\subsection{Alteration of Ginsenoside in American Ginseng Roots Inoculated with Fusarium spp.}

Six ginsenosides, $\mathrm{Rg}_{1}, \mathrm{Re}, \mathrm{Rb}_{1}, \mathrm{Rc}, \mathrm{Rb}_{2}$, and $\mathrm{Rd}$, were detected using high performance liquid chromatography (HPLC) and quantified by comparing them to standards. The corresponding HPLC calibration curves for $\mathrm{Rg}_{1}, \mathrm{Re}, \mathrm{Rb}_{1}, \mathrm{Rc}, \mathrm{Rb}_{2}$, and $\mathrm{Rd}$ were: $Y=216,944 X+5432(0.0163-4.16 \mu \mathrm{g}$, $\left.R^{2}=0.9996\right), Y=198,382 X+52,512\left(0.129-33.1 \mu \mathrm{g}, R^{2}=0.9993\right), Y=177,784 X+52,102$ 
(0.127-32.5 $\left.\mu \mathrm{g}, R^{2}=0.9995\right), Y=173,823 X+48,412\left(0.132-33.9 \mu \mathrm{g}, R^{2}=0.9996\right), Y=180,668 X+$ $3131\left(0.0155-3.96 \mu \mathrm{g}, R^{2}=0.9996\right), Y=210,351 X+7109\left(0.0177-4.52 \mu \mathrm{g}, R^{2}=0.9995\right)$, respectively, where $Y$ is the peak area in HPLC, and $X$ is the concentration of the corresponding compound.

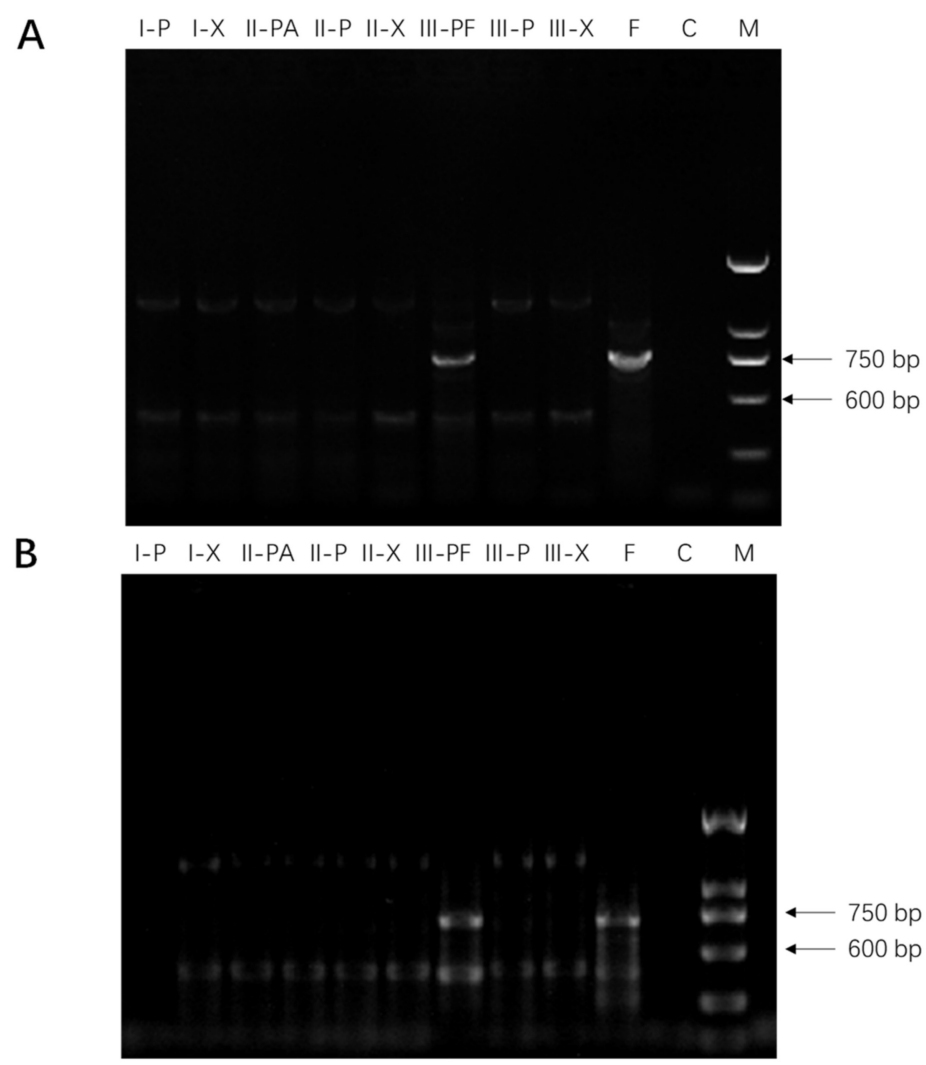

Figure 1. Detection of F. solani (strain F19, panel (A)) and F. oxysporum (strain C1, panel (B)) in American ginseng root tissues using polymerase chain reaction (PCR). Gel lanes show the presence of PCR products from left to right: (I-P), phloem of part I; (I-X), xylem of part I; (II-PA), phloem under PDA plugs of part II; (II-P), area adjacent to PDA plugs of part II; (II-X), xylem of part II; (III-PF), phloem under Fusarium culture plug of part III; (III-P), adjacent Fusarium culture plugs of part III; (III-X), xylem of part III; (F), positive control (Fusarium spp.), (C), negative control (no DNA template), and (M), DNA ladder.

The slopes of the six calibration curves followed the order $\operatorname{Rg}_{1}>\operatorname{Rd}>\operatorname{Re}>\mathrm{Rb}_{2}>\mathrm{Rb}_{1}>\mathrm{Rc}$, indicating that the HPLC detection sensitivities for the contents of these ginsenosides were reduced in this order. A representative HPLC elution profile of ginsenoside $\mathrm{Rg}_{1}, \mathrm{Re}, \mathrm{R} \mathrm{b}_{1}, \mathrm{Rc}, \mathrm{Rb} \mathrm{b}_{2}$, and $\mathrm{Rd}$, in healthy ginseng roots is shown in Figure 2. The mean values \pm SD of specific recovery rates with five replicates are $(\%): \operatorname{Rg}_{1} 99.35 \pm 1.18 ; \operatorname{Re} 99.85 \pm 1.76 ; \mathrm{Rb}_{1} 97.25 \pm 1.30 ; \mathrm{Rc} 100.21 \pm 0.43$; $\mathrm{Rb}_{2} 97.89 \pm 1.93$; and $\mathrm{Rd} 95.11 \pm 0.97$. Regardless of the tissue type (xylem or phloem), the difference in ginsenoside content between the three ginseng root parts (part I, II, and III) was not significant in healthy ginseng roots (Figure 3). 


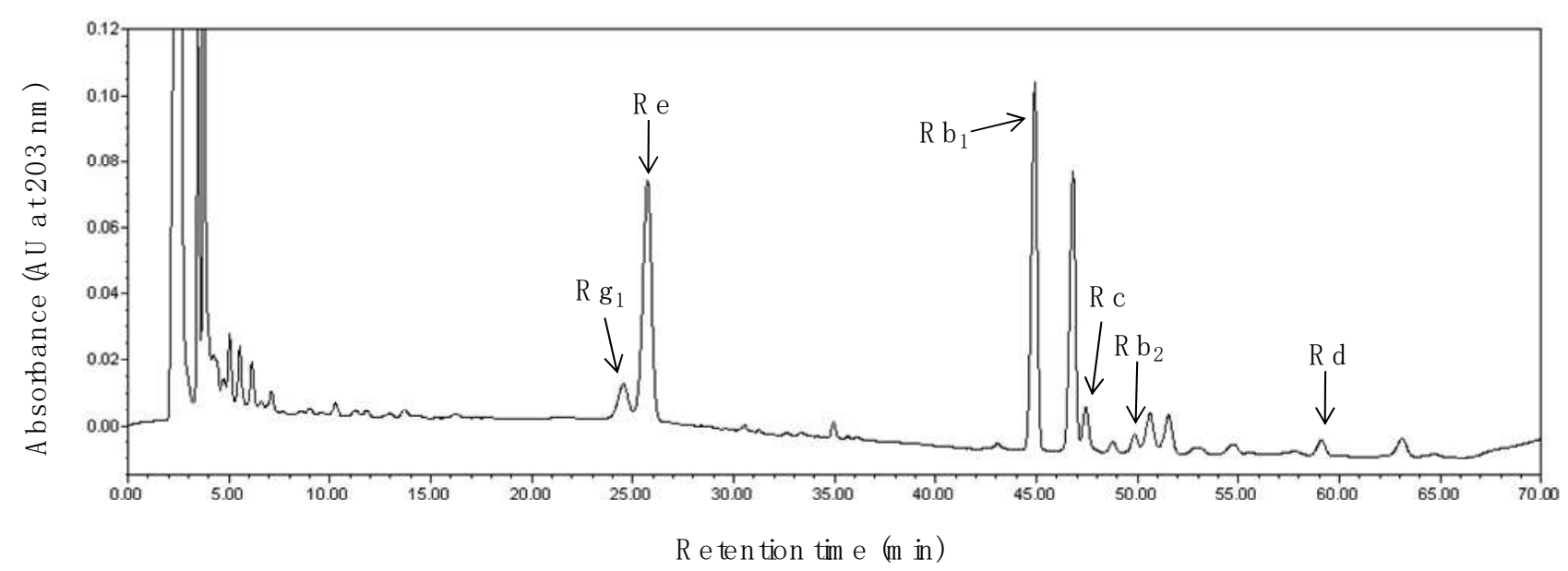

Figure 2. Representative retention peaks of a high performance liquid chromatography (HPLC) separation of ginsenoside $\mathrm{Rg}_{1}, \mathrm{Re}, \mathrm{Rb}_{1}, \mathrm{Rc}, \mathrm{R} \mathrm{b}_{2}$, and $\mathrm{Rd}$, extracted from American ginseng roots.
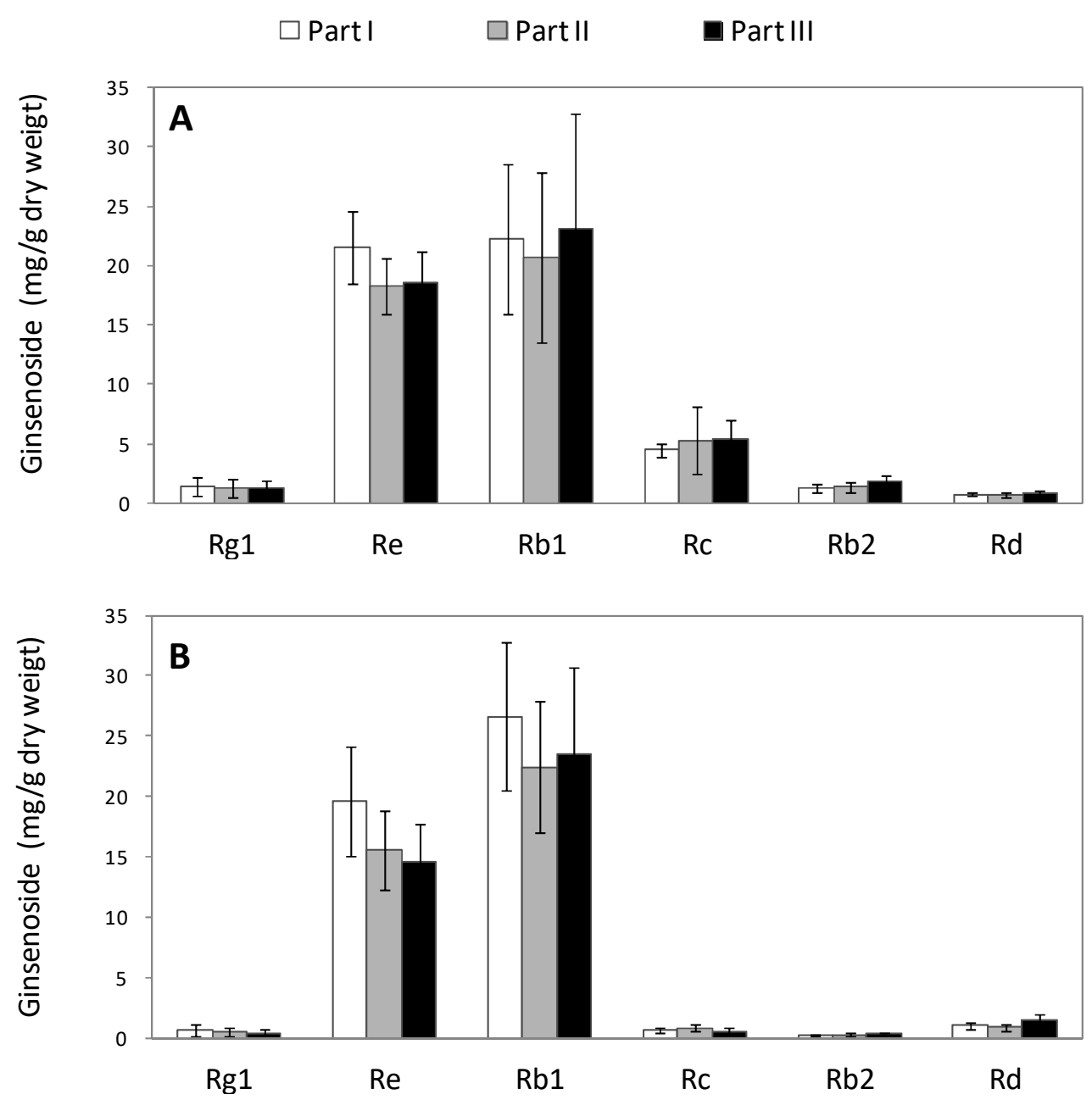

Figure 3. Measurement of ginsenoside $\left(\mathrm{Rg}_{1}, \mathrm{Re}, \mathrm{R} \mathrm{b}_{1}, \mathrm{Rc}, \mathrm{Rb} \mathrm{b}_{2}\right.$, and $\left.\mathrm{Rd}\right)$ contents $(\mathrm{mg} / \mathrm{g}$ dry weight) in three root parts (I, II, and III) of healthy American ginseng in: (A) phloem and (B) xylem. Mean values of ginsenoside amongst the three root parts (I, II and III) are not significantly different at $\alpha=0.05(p>0.05)$, analyzed using Fisher's least significant difference (LSD) test. 
No significant difference was found in contents of ginsenoside $\mathrm{Rg}_{1}, \mathrm{Re}, \mathrm{Rc}, \mathrm{Rb}$, and $\mathrm{Rd}$ among different root parts using two-way analysis $(p>0.05)$, while a significant difference was observed among different tissue types $(p<0.05)$ (Table 1$)$. For the contents of $\mathrm{Rb}_{1}$, no significant difference was found either in root parts or in tissue types. Moreover, for all the six ginsenosides, no significant interaction was observed between root parts and tissue types.

Table 1. Summary of $p$ values of the analysis of variance of ginsenoside contents in healthy ginseng roots.

\begin{tabular}{lcccccc}
\hline & $\mathbf{R g}_{1}$ & $\mathbf{R e}$ & $\mathbf{R b _ { 1 }}$ & $\mathbf{R c}$ & $\mathbf{R b} 2$ & $\mathbf{R d}$ \\
\hline Part & 0.698 & 0.051 & 0.659 & 0.656 & 0.071 & 0.079 \\
Tissue type & 0.001 & 0.011 & 0.406 & 0.000 & 0.000 & 0.005 \\
Interaction between part and tissue type & 0.998 & 0.898 & 0.831 & 0.676 & 0.235 & 0.398 \\
\hline
\end{tabular}

After seven days of treatment with PDA, the contents of all six ginsenosides in PDA plug-treated tissue (II-PA), including $\mathrm{Rg}_{1}, \mathrm{Re}, \mathrm{Rb}_{1}, \mathrm{Rc}, \mathrm{Rb}_{2}$ and $\mathrm{Rd}$, were not significantly different from those in untreated tissue (I-P) at 0 days (Figure 4). After seven days of inoculation with $F$. solani, $\mathrm{Rd}$ and $\mathrm{Rc}$ in the infected phloem tissue (III-PF) significantly increased by $35 \%$ and $56 \%$ compared to that treated with PDA plug, respectively (Figure 4B). In the area of phloem tissue adjacent to the Fusarium inoculation spot (III-P), no lesions were observed, and the Rd and Rc contents remain unchanged.

$F$. solani infection significantly decreased the levels of $\mathrm{Rg}_{1}$ in the infected tissue by $18 \%$ compared to PDA plug treatment, while $\operatorname{Rg}_{1}$ did not change significantly in the area adjacent to Fusarium inoculation. However, infections by $F$. solani had no significantly effect on $\mathrm{Re}, \mathrm{Rb}_{1}$, and $\mathrm{Rb}_{2}$ content in infected phloem tissues.
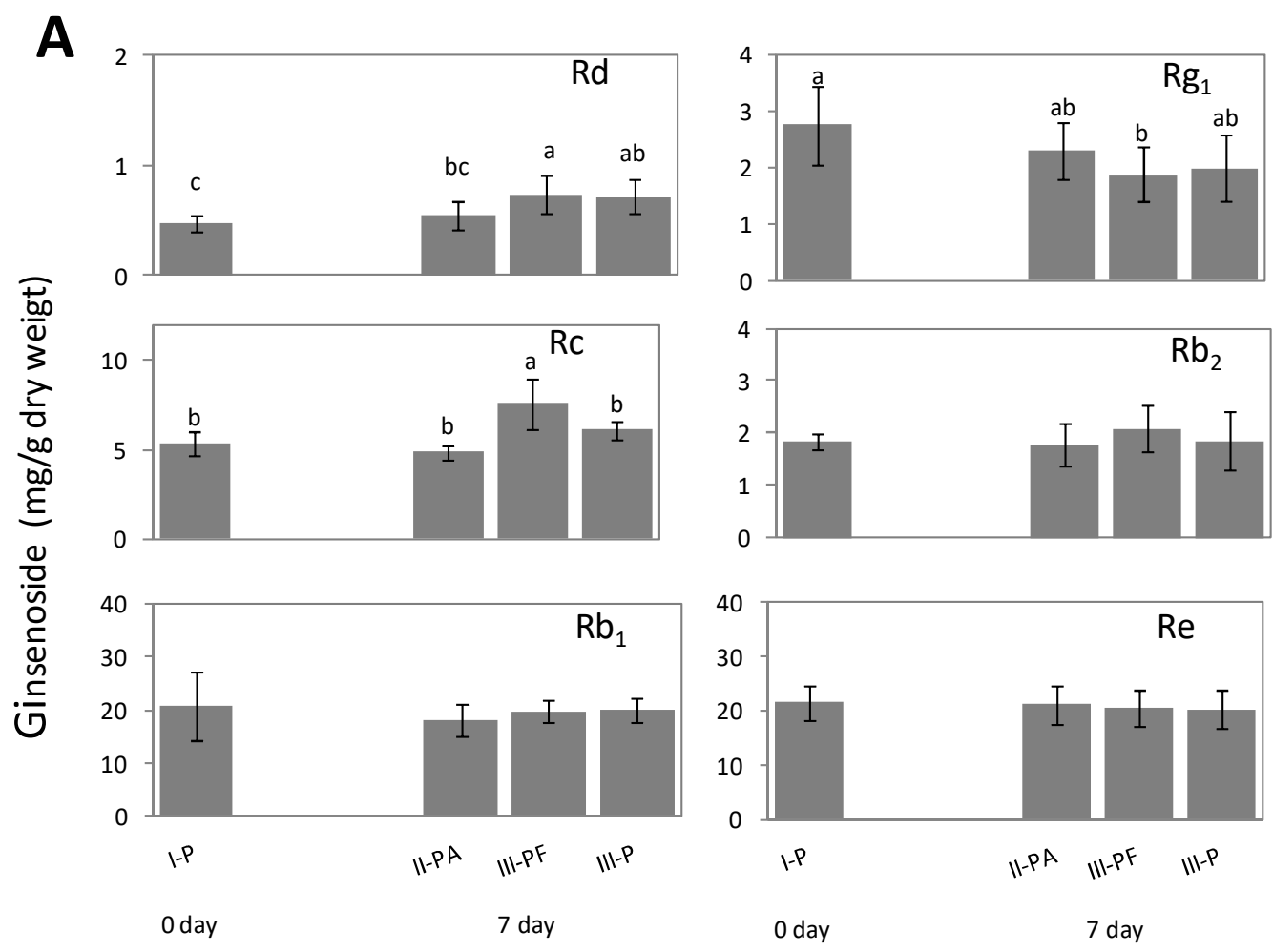

Figure 4. Cont. 

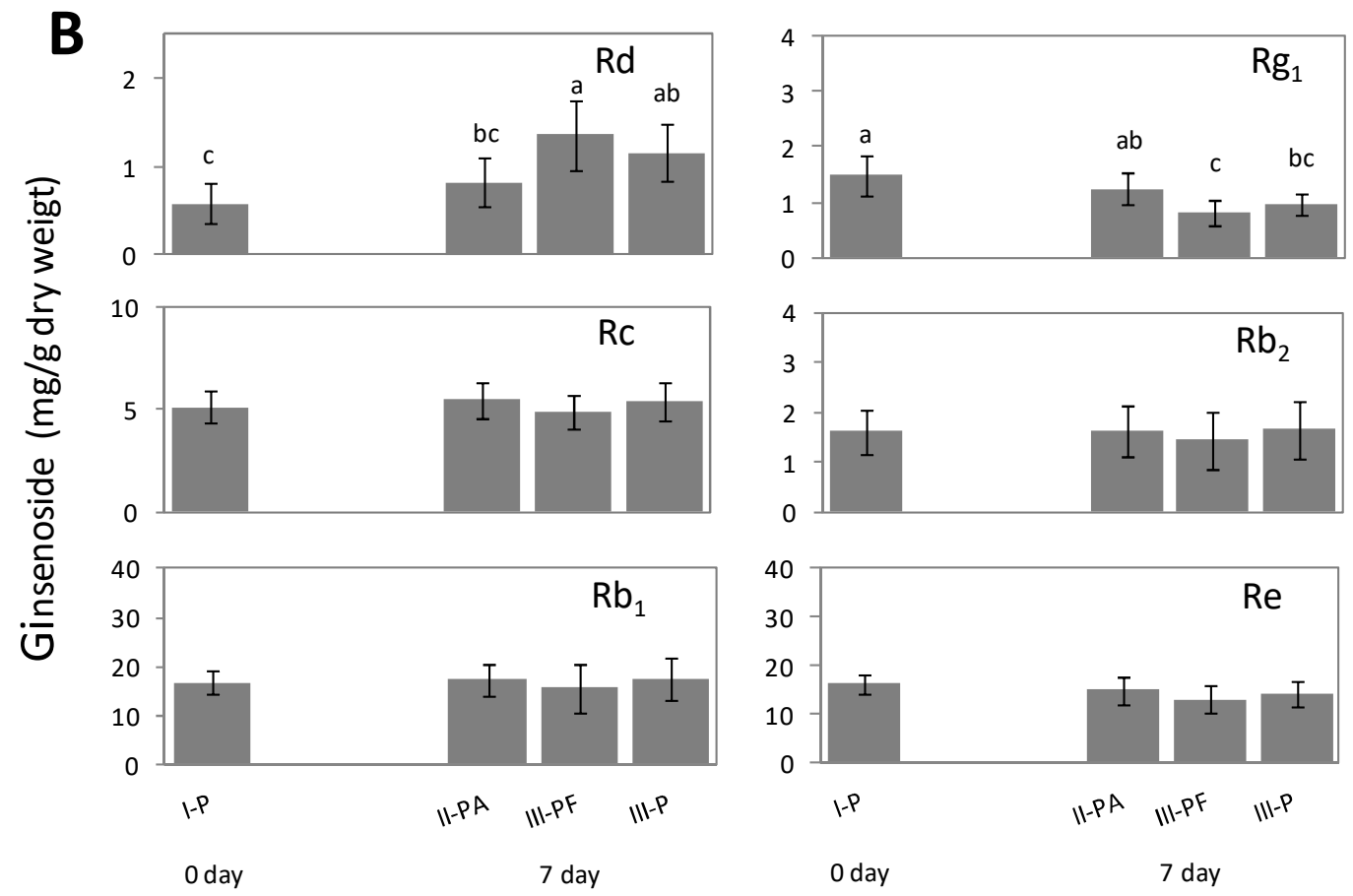

Figure 4. Contents of ginsenoside $\mathrm{Rg}_{1}, \mathrm{Re}, \mathrm{Rb}_{1}, \mathrm{Rc}, \mathrm{Rb}_{2}$, and $\mathrm{Rd}$ of American ginseng roots detected using HPLC in phloem tissues of the three parts (I, II, and III), including untreated (I-P), PDA-plugged (II-PA), Fusarium culture (III-PF) and untreated area adjacent to Fusarium culture (III-P). Samples were collected at 0 and 7 days after inoculation with (A) Fusarium solani; and (B) F. oxysporum. Mean values followed by the same letter or no letter were not significantly different $(p<0.05)$ in each ginsenoside (a panel in the figure), while followed by different letters were significantly different $(p>0.05)$, analyzed using Fisher's least significant difference (LSD) test.

After seven days of inoculation with $F$. oxysporum, the content of the ginsenoside $\mathrm{Rd}$ in infected phloem tissue significantly increased by $65 \%$ compared to the PDA plug treatment (Figure 4B). There was also a trend of about $40 \%$ increase in the tissue adjacent to the Fusarium culture, but no significance was found compared to $\mathrm{Rd}$ content in PDA treatment. The content of $\operatorname{Rg}_{1}$ in the phloem tissues in direct contact with Fusarium culture was significantly decreased by $36 \%$ compared to PDA plug treatment. $\operatorname{Rg}_{1}$ content in the area adjacent to Fusarium inoculation also decreased by $23 \%$, but no significant difference was detected when compared to $\mathrm{Rg}_{1}$ in PDA treatment. Moreover, infection by $F$. oxysporum had no effect on levels of $\mathrm{Re}, \mathrm{Rb}_{1}, \mathrm{Rc}$ and $\mathrm{Rb}_{2}$ in infected phloem tissues.

Ginsenoside contents were also measured in the xylem of ginseng roots after inoculation of F. solani or F. oxysporum. Infection by either of the two Fusarium species did not affect the level of any of the six ginsenosides in the corresponding xylem tissues (Figure 5). 

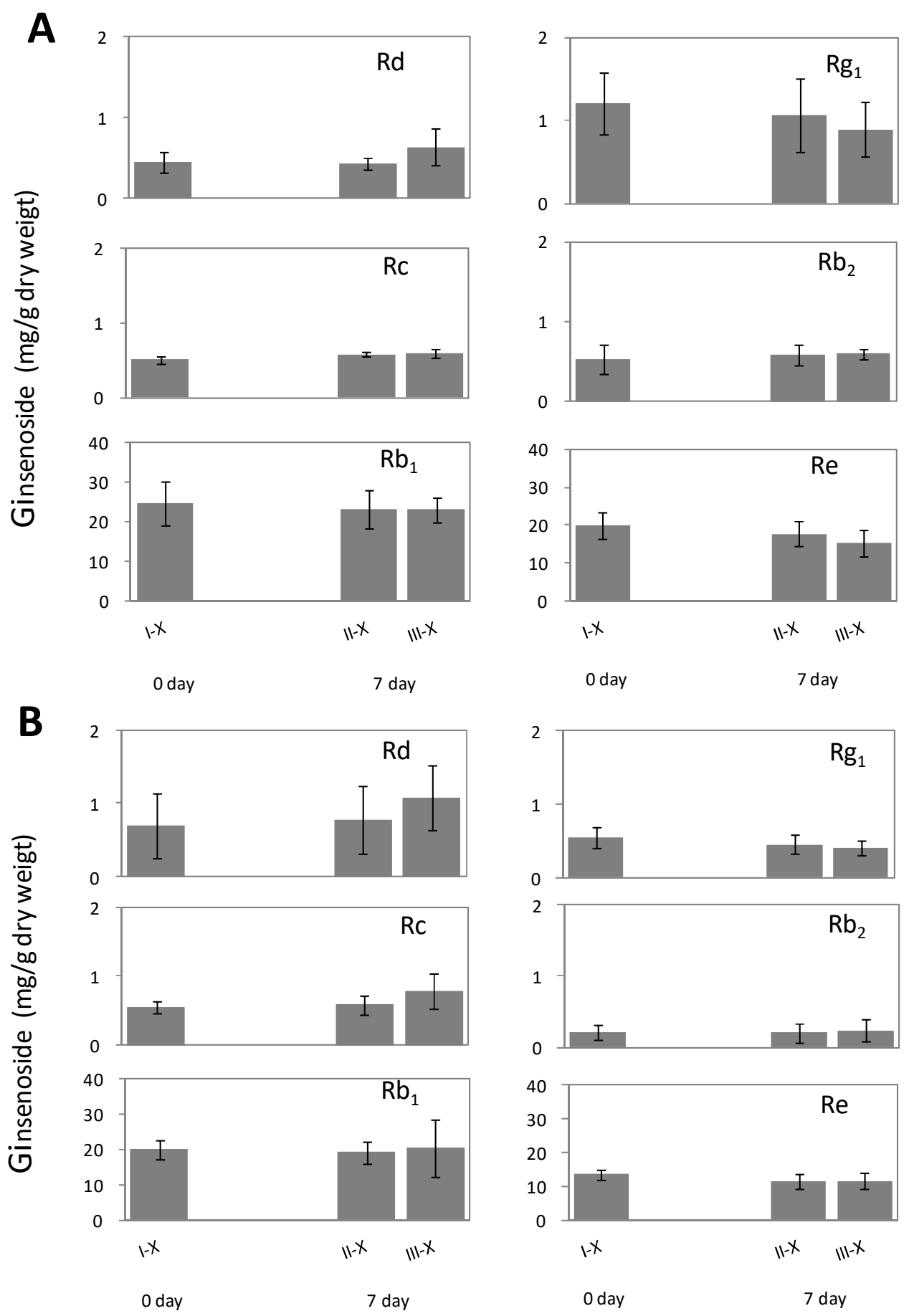

Figure 5. Measurements of ginsenoside $\mathrm{Rg}_{1}, \mathrm{Re}, \mathrm{Rb}_{1}, \mathrm{Rc}, \mathrm{Rb_{2 }}$, and $\mathrm{Rd}$ in xylem tissue of American ginseng roots after inoculation for 0 or 7 days with: (A) Fusarium solani and (B) F. oxysporum. Root treatments include untreated (I-X), PDA plug (II-X), and Fusarium culture (III-X). Bars of mean values of ginsenoside with no letters indicate no significant difference $(p>0.05)$, analyzed using Fisher's least significant difference (LSD) test.

\subsection{Metabolic Effect of Fusarium spp. on the Concentrations of Ginsenoside}

After seven days of incubation on ginsenoside-amended Czapek medium, a white to cream coloration, and dense mycelia texture were observed in the group inoculated with $F$. solani or $F$. oxysporum 
conidia. All six ginsenosides were detected in the Czapek medium of Fusarium culture after seven days of incubation with $F$. solani or $F$. oxysporum.

Compared to the amount initially added to the medium, $\mathrm{Rg}_{1}, \mathrm{Re}, \mathrm{Rb} \mathrm{b}_{1}, \mathrm{Rc}, \mathrm{Rb}_{2}$, but not $\mathrm{Rd}$, were substantially depleted in the medium with $F$. solani or $F$. oxysporum (Figure 6 ). The degradation of these ginsenosides occurred after three to five days of co-culturing with the fungi (Figure 6). These results suggested that both $F$. solani and $F$. oxysporum were capable of inducing metabolic changes of major ginsenosides in American ginseng roots.

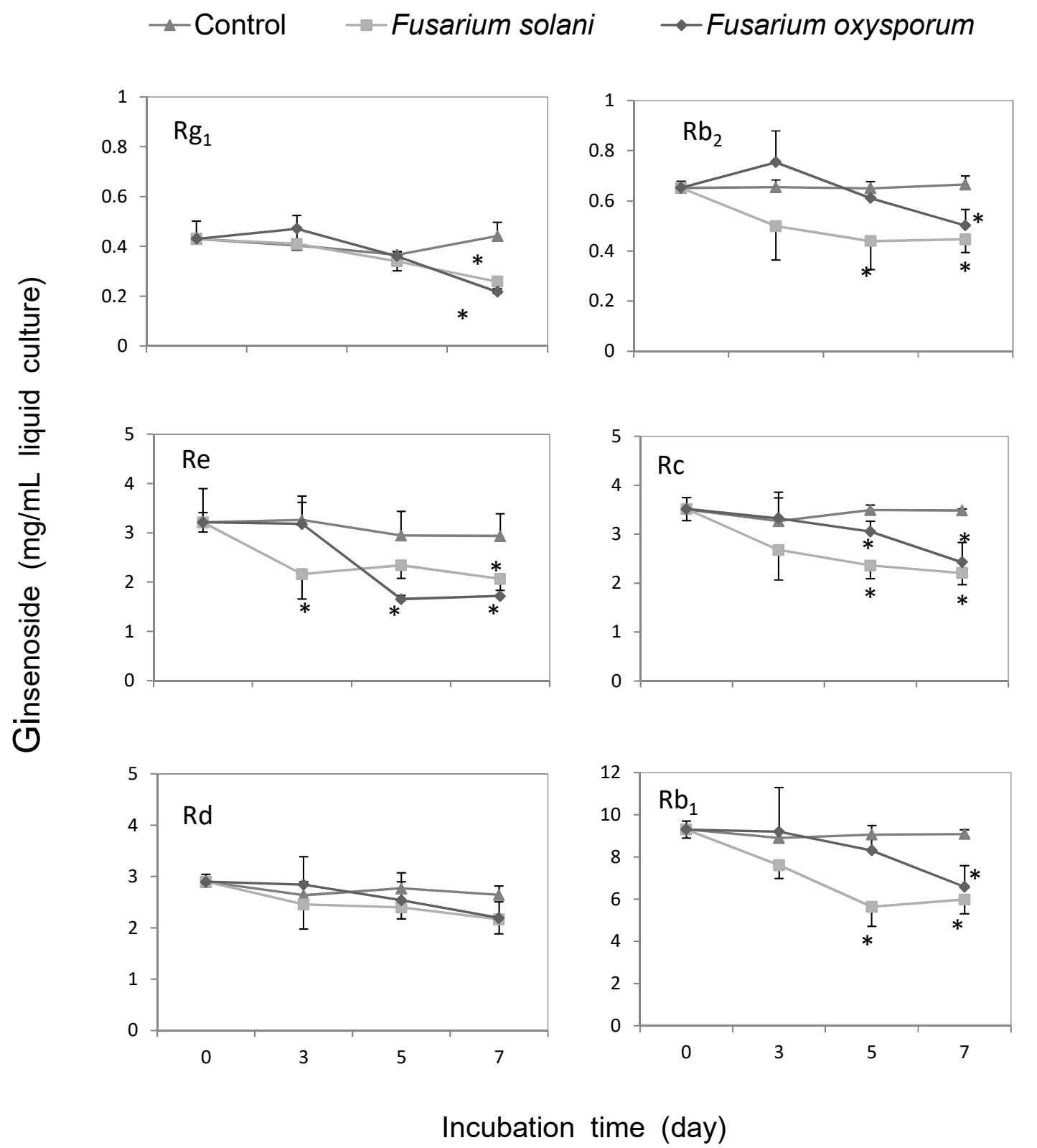

Figure 6. Metabolic effect of Fusarium solani and F. oxysporum on the concentrations of ginsenoside. Ginsenoside $\mathrm{Rg}_{1}, \mathrm{Rb}_{2}, \mathrm{Re}, \mathrm{Rc}, \mathrm{Rd}$, and $\mathrm{Rb}_{1}$, were incubated with $F$. solani (square) or F. oxysporum (diamond) for 0 to 7 days. The values of ginsenoside content followed by an asterisk indicate a significant difference with control group (trilateral) at $\alpha=0.05(p<0.05)$, as analyzed using Fisher's least significant difference (LSD) test. 


\subsection{Discussion}

We have found that Fusarium growth was strictly limited to the infected phloem tissues, as shown by the proliferation of Fusarium equiseti in American ginseng root [26]. After 7 days of inoculation, $\mathrm{Rg}_{1}, \mathrm{Rd}$ contents significantly changed in the phloem region tissues infected by both $F$. solani and $F$. oxysporum, but $\mathrm{Rc}$ content was only affected by $F$. solani, whereas $\mathrm{Rb}_{1}$, $\mathrm{Re}$ and $\mathrm{Rb}_{2}$ did not significantly change in Fusarium-infected phloem tissues. None of the ginsenosides was significantly altered in root phloem tissues where no Fusarium spp. mycelial growth was detected. This suggests that no direct chemical transduction occurs from infected phloem to xylem, and the ginsenoside alteration is likely a local reaction in American ginseng phloem tissue against Fusarium infection.

Ginsenosides were biodegraded when co-incubated with $F$. solani and $F$. oxysporum cultures on Czapek medium, indicating a direct metabolism of ginsenoside by the fungi. This is in agreement with the fact that the contents of ginsenoside $\mathrm{Rg}_{1}, \mathrm{Rd}, \mathrm{Rb} \mathrm{b}_{1}, \mathrm{Re}, \mathrm{Rc}$, and $\mathrm{Rb_{2 }}$ were reduced by $9 \%$ to $44 \%$ in rusty root-affected epidermal and cortical tissues of American ginseng roots in an agricultural field [12]. In this study, the decrease of $\operatorname{Rg}_{1}$ in root tissues is likely attributed to the degradation by the Fusarium pathogens. Rc and $\mathrm{Rd}$ increased in American ginseng roots seven days after inoculation by the two Fusarium species. Rc increased in F. solani-infected American ginseng root tissues followed the up-regulation of ginsenoside $\mathrm{Rb}_{1}$ at $72 \mathrm{~h}$ after $F$. solani inoculation, showing a similar response with $\mathrm{Rb}_{1}$ to fungi infection [21]. Rd can be transformed from other ginsenosides, i.e., $\mathrm{Rc}, \mathrm{Rb}_{1}$ and $\mathrm{Rb}$, by removing terminal saccharide residues on C-20 (Scheme 1). Also, previous reports discovered that the terminal sugar units of ginsenoside $\mathrm{Rc}, \mathrm{Rb}_{1}$ or $\mathrm{Rb}_{2}$ could be cleaved by glycosidase produced in many fungi, such as Pythium irregulare [27] and Cylindrocarpon destructans [25]. Moreover, pathogenic fungi such as tomato pathogen Cladosporium fulvum transformed ginsenoside $\mathrm{Rb}_{1}$ into $\mathrm{Rd}$ as a final product [28]. The Fusarium spp. used in our experiment might show the similar characteristic on ginsenoside decomposition. Here we suggest that the promotion of Rd in infected phloem tissues of ginseng root is probably derived from decomposition of other 20(S)-protopanaxadiol saponins such as $\mathrm{Rb}_{1}$ which was previously induced by the Fusarium spp. in early stage of infection [21]. Whether the increase of $\mathrm{Rd}$ in infected roots is correlated with its chemical defense against the two Fusarium spp. is still unclear. It will be of great interest for future studies to determine when and how these transformations occurred and are regulated under different pathogen infection status. i.e., short term versus long term. We observed different responses in ginsenosides to the infection by $F$. solani and F. oxysporum: $\mathrm{Rg}_{1}, \mathrm{Rc}$, and $\mathrm{Rd}$ were affected by $F$. solani, while only $\mathrm{Rg}_{1}$ and $\mathrm{Rd}$ were affected by $F$. oxysporum. Most likely the potentially different alteration of ginsenoside contents in ginseng roots is caused differently by the two Fusarium isolates' infection. This type of difference has also been observed in Leptographium wingfieldii and Ophiostoma canum infected Scots pine resulting in different changes of monoterpene contents [29]. However, the specific mechanisms remain unclear and other Fusarium species still need to be examined.

The amounts of ginsenoside in infected American ginseng roots can be affected by both plant metabolism and fungal biodegradation, which may explain the different results seen in the ginsenoside alteration in ginseng roots and Czapek medium. Rc and Rd were increased in the Fusarium-infected root tissues, although they were biodegraded by the Fusarium spp. in vitro, showing a similar increased response as found for $\mathrm{Rb}_{1}$ in our previous study [21]. 

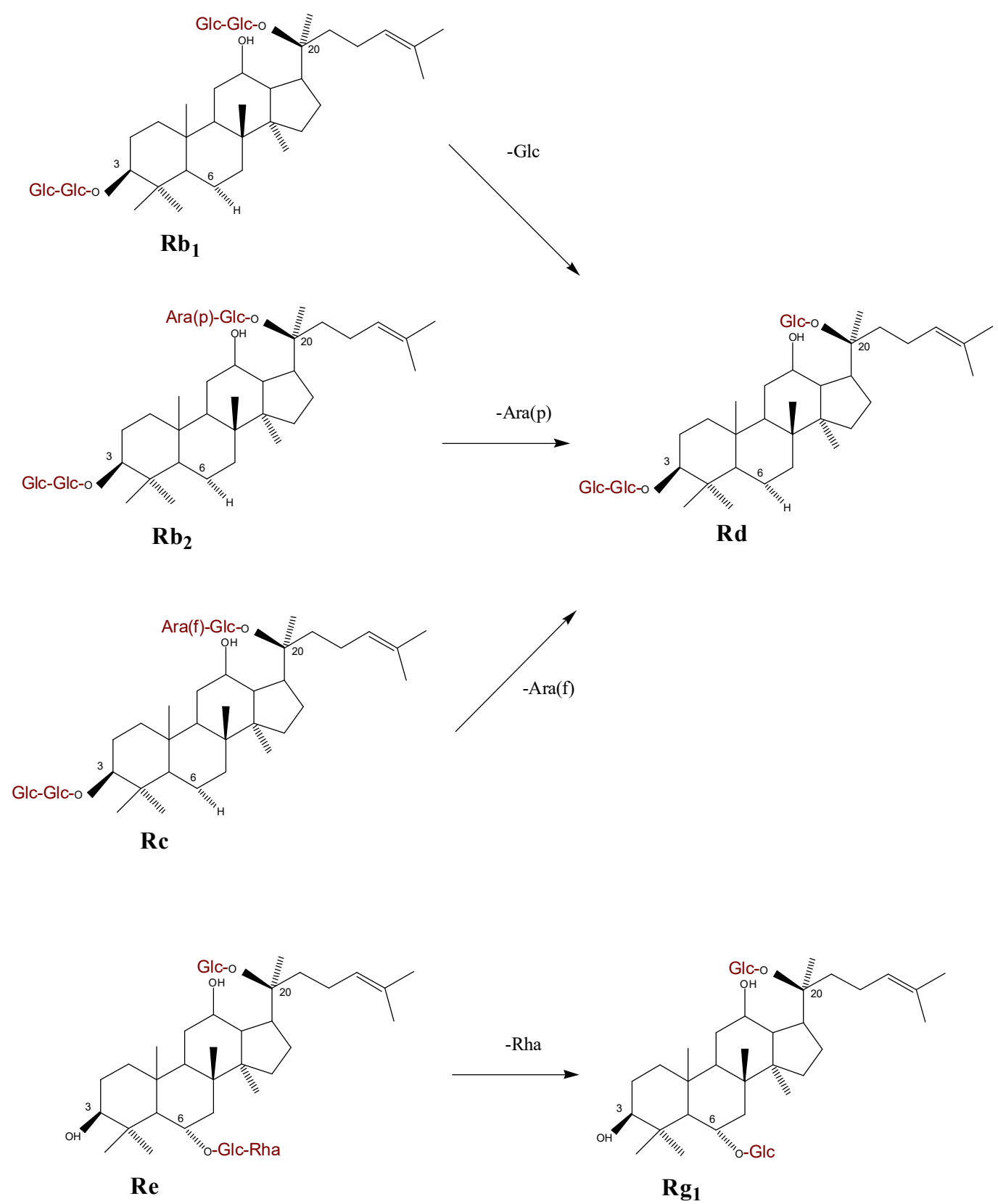

Scheme 1. Chemical structures and transformations of ginsenoside commonly isolated from American ginseng roots according to Leung and Wong [3], and Yousef and Bernards [27].

This likely indicates the synthesis of ginsenoside Rc and Rd were obviously induced by the two pathogen infections in the plant, and needs to be confirmed in further studies. Another reason for Rd increase is that it might be a metabolite of $R b_{1}, R c$, and $R b_{2}$ formed by removal of terminal saccharide residues on $C-20 . R b_{1}$ and $R b_{2}$ did not significantly change in the infected root tissues, so we hypothesize that the amount of synthesis of these compounds equals the amount degraded. However, this needs to be further confirmed. $\operatorname{Rg}_{1}$ significantly decreased in infected root tissues, while $\mathrm{Re}$ showed no significant change but rather a slight decrease. It has been confirmed that the syntheses of $\operatorname{Rg}_{1}$ and $\operatorname{Re}$ are not increased by the stimulation of $F$. solani and $F$. oxysporum [21]. Thus, once ginseng roots are infected, $\operatorname{Rg}_{1}$ and $R e$ are degraded by the fungi. Due to the fact the content of $\operatorname{Rg}_{1}$ is lower than that of Re in ginseng root, the degraded amount caused a more notable effect on decrease of 
$\operatorname{Rg}_{1}$ than Re. Therefore, the content of ginsenoside in ginseng roots might be a combined consequence of pathogen metabolism and plant synthesis.

\section{Experimental Section}

\subsection{American Ginseng Roots and Fungal Inoculums}

Four-year-old healthy and fresh American ginseng roots were dug from a commercial farm in Beijing, China in October 2008. Roots of about $12 \mathrm{~cm}$ in length (equivalent to 15 to $20 \mathrm{~g}$ in dry weight) were carefully bagged, transported to the laboratory, and stored at $4{ }^{\circ} \mathrm{C}$ for later use. Cultures of Fusarium solani (isolate F19) and F. oxysporum (isolate $\mathrm{C} 1$ ) were obtained from reddish-brown discolored rotten areas of naturally-infected American ginseng roots in our previous study, and their isolation, identification, and pathogenicity were previously described [21]. The mycelium of each fungal isolate was transferred and cultured on potato dextrose agar (PDA: $200 \mathrm{~g}$ of potato, $20 \mathrm{~g}$ of dextrose, $13 \mathrm{~g}$ of agar, and brought up to $1 \mathrm{~L}$ with distilled water) plates at $25{ }^{\circ} \mathrm{C}$ for seven days before inoculation.

\subsection{Root Treatments}

Prior to the treatment, ginseng roots of approximately $12 \mathrm{~cm}$ in length were prepared by removing all the fine roots with a sterile scalpel. The taproots left were washed using tap water and then soaked in $75 \%$ ethanol for five minutes, followed by rinsing three times with sterile distilled water according to the previous report [21]. Each root piece was then transected into three sequential parts from the root tip to the base. The top part (part I), around three centimeters in length and eight grams in weight, was left untreated. The middle part (part II), around three centimeters in length and eight grams in weight, and the bottom part (part III), about five centimeters in length and also eight grams in weight, were disinfested by $3.25 \% \mathrm{NaClO}$ for $10 \mathrm{~min}$ and then rinsed three times with sterile distilled water. Then part II was attached with pathogen-free PDA plugs on the surface as a control, while part III was inoculated by placing a mycelial plug (six millimeters in diameter) of each Fusarium isolate (F19 or $\mathrm{C} 1$ ) on the central surface of the root segment as a treatment. The treated root (part III) and corresponding root part II with PDA plugs were then incubated at $25^{\circ} \mathrm{C}$ in the dark for seven days.

For molecular diagnosis of the pathogen and analysis of ginsenoside contents, ginseng root parts I (the untreated group), II and III were peeled from the visible cambium. The outside tissue of cambium was considered as phloem, while the inside part was xylem. Moreover, phloem tissues underneath the mycelium of parts III (showing lesions) or control plugs of parts II (medium only) were separated from the adjacent phloem tissues. A total of eight different sample groups were analyzed, including phloem of root part I (I-P), xylem of part I (I-X), phloem under PDA plug of part II (II-PA) and adjacent area (II-P), xylem under the plug of part II (II-X), phloem under Fusarium culture plug of part III (III-PF) and adjacent area (III-P), and xylem of part III (III-X) (Figure 7). There were five replicates per treatment. All the eight groups were used for molecular detection of the two Fusarium spp. as described below, while seven groups were used for ginsenoside quantification, including I-P as background check, II-PA as a control, III-PF and III-P as inoculated groups of phloem; I-X, II-X, and III-X as background check, control and inoculated groups of xylem, respectively. 


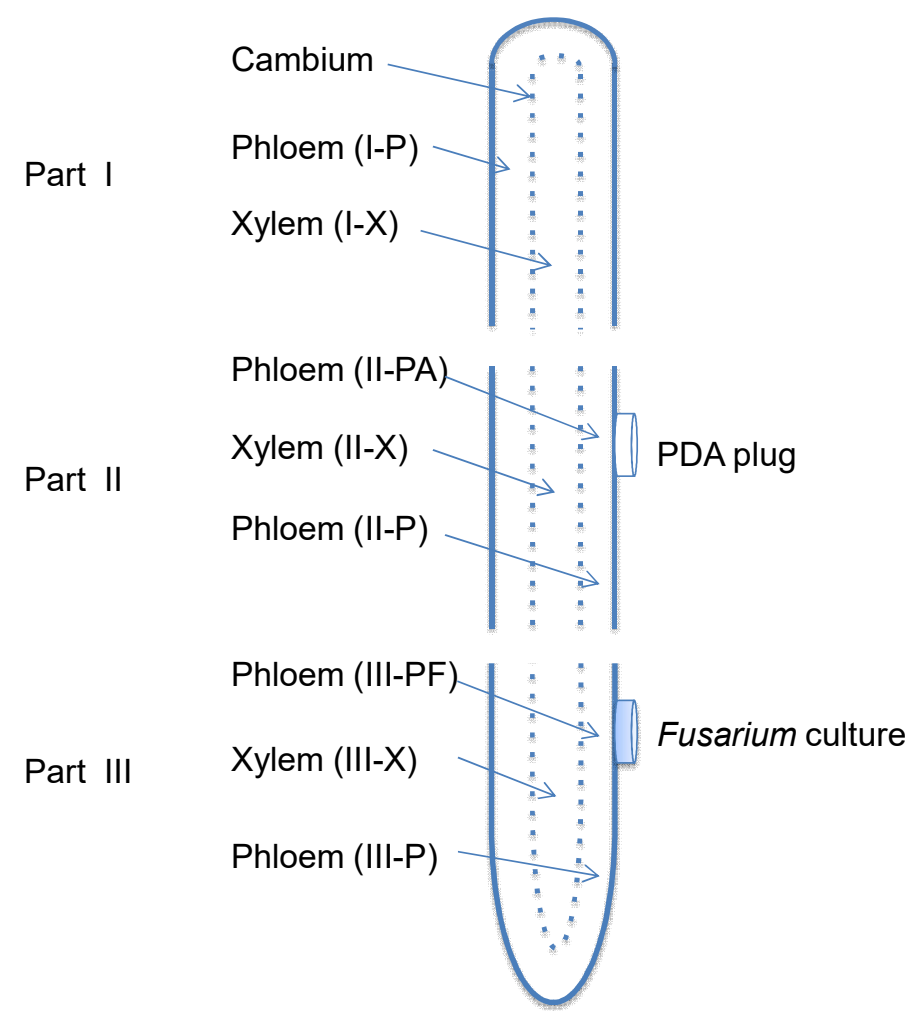

Figure 7. Schematic diagram of xylem $(\mathrm{X})$ and phloem $(\mathrm{P})$ tissues of a dissected taproot of American ginseng showing the three parts (I, II, and III) of sampling and inoculation with Fusarium solani or F. oxysporum.

\subsection{Molecular Detection of Fusarium spp. in American Ginseng Roots}

To study the effect of fungal infection, we first confirmed that inoculation of American ginseng roots with both $F$. solani and $F$. oxysporum leads to consistent phenotypical changes. In order to investigate the ginsenoside production in different root tissues, the infected area in American ginseng root after inoculation by the two Fusarium species needed to be confirmed in this experiment. We used a PCR-based molecular detection assay to determine the extent of fungal infection in infected American ginseng roots. The treated root pieces were sterilized as described by Guo et al. [30], treated with $75 \%$ ethanol for one minute, then $3.25 \% \mathrm{NaClO}$ for five minutes, followed by washing three times with sterile distilled water and once with 75\% ethanol. The DNA was extracted using the CTAB method as previously described [31]. Briefly, root sections were crushed with a glass pestle in a mortar under liquid nitrogen, transferred into a $1.5 \mathrm{~mL}$ microcentrifuge tube containing $600 \mu \mathrm{L}$ $\mathrm{CTAB}$, and then incubated at $65{ }^{\circ} \mathrm{C}$ for $60 \mathrm{~min}$. After centrifugation at $10,625 \mathrm{~g}$ for $10 \mathrm{~min}(1-14$, Sigma Inc., Deisenhofen, Germany), the supernatant was transferred into a fresh $1.5 \mathrm{~mL}$ microcentrifuge tube, mixed with equal volume of Tris saturated phenol: chloroform: isoamyl alcohol at the volume ratio of 25:24:1, and centrifuged at 10,625 $\mathrm{g}$ for $10 \mathrm{~min}$. The DNA in supernatant was then precipitated by isopropanol at $-20{ }^{\circ} \mathrm{C}$ for $60 \mathrm{~min}$, washed with $70 \%$ ethanol, and re-suspended into $20 \mu \mathrm{L}$ sterile distilled water.

A part of the elongation factor 1alpha $(\mathrm{EF}-1 \alpha)$ gene was amplified with the primer pair EF1T 5'-ATGGGTAAGGAGGACAAGAC-3' and EF2T 5'-GGAAGTACCAGTGATCATGTT-3' [32]. Total DNA isolated from eight sample groups as described above together with the negative 
(no template DNA added) and positive controls (template DNA was isolated from mycelium of two Fusarium spp.) were amplified by PCR using the following settings of thermal cycler (Tprofessional, Biometra Inc., Göttingen, Germany): $94{ }^{\circ} \mathrm{C}$ for $85 \mathrm{~s}$, followed by 35 cycles of $95{ }^{\circ} \mathrm{C}$ for $35 \mathrm{~s}, 57^{\circ} \mathrm{C}$ for $55 \mathrm{~s}$ and $72{ }^{\circ} \mathrm{C}$ for $60 \mathrm{~s}$, then a final extension at $72{ }^{\circ} \mathrm{C}$ for $10 \mathrm{~min}$. Amplified DNA products were electrophoresed in 1\% agarose gel in $1 \times$ TAE buffer $(40 \mathrm{mM}$ Tris-acetate, $1 \mathrm{mM}$ EDTA, $\mathrm{pH} 8.0)$ at $100 \mathrm{~V}$ for $30 \mathrm{~min}$. The gel was stained with Goldview (0.002\% v/v, Tiangen Biotech Co., Ltd., Beijing, China), and examined under a UV light.

\subsection{Quantification of Ginsenoside from Root Extracts}

To better understand how ginsenosides are altered by $F$. solani and $F$. oxysporum at the late stage of infection, the contents of six major ginsenosides were analyzed in American ginseng roots using high performance liquid chromatography (HPLC, 600-486-717, Waters Inc., Milford, MA, USA) following the published method with slight modifications [33]. The root fragments from each treatment group were chopped into small pieces (approximately $1 \times 1 \times 0.5 \mathrm{~cm}$ ) and dried at $45^{\circ} \mathrm{C}$ for approximately three days, when consistent dry weight was obtained. Dried root pieces were then ground into powders using a blender (Linda Machinery Co., Ltd., Taizhou, China), sieved (sieve size opening $0.422 \mathrm{~mm}$ ). An aliquot of $50 \mathrm{~mL}$ of water-saturated $n-\mathrm{BuOH}$ was added to $0.5 \mathrm{~g}$ of dry powdered roots to extract ginsenoside at $40{ }^{\circ} \mathrm{C}$ for 60 min with an ultrasonic extractor (Kunshan Ultrasonic Machinery Co., Ltd., Suzhou, China). The solution was filtered through a piece of quantitative filter paper (Special Paper Industry Co., Ltd., Hangzhou, China), and then $25 \mathrm{~mL}$ were transferred to an evaporating dish to dry. The dried evaporation residue was redissolved in $50 \% \mathrm{MeOH}$ (aq) $(5 \mathrm{~mL})$ and filtered through a $0.45 \mu \mathrm{m}$ nylon membrane filter (Jinteng Experiment Equipment Co., Ltd., Tianjin, China). The filtrated solution was stored at $4{ }^{\circ} \mathrm{C}$ for further analysis.

Standards of $\mathrm{Rg}_{1}, \mathrm{Re}, \mathrm{Rb}_{1}, \mathrm{Rc}, \mathrm{Rb}_{2}$, and $\mathrm{Rd}$ for HPLC were purchased from the National Institute for the Control of Pharmaceutical and Biological Products (Beijing, China). For HPLC elution, $10 \mu \mathrm{L}$ of extracted liquid was injected into an Apollo ${ }^{\circledR} \mathrm{RP}$ C18 column $(5 \mu \mathrm{m}, 150 \mathrm{~mm} \times 4.6 \mathrm{~mm}$, Alltech Inc., Deerfield, IL, USA). For the analysis of five ginsenosides $\mathrm{Rg}_{1}, \mathrm{Re}, \mathrm{Rb}_{1}, \mathrm{Rb} \mathrm{b}_{2}$, and $\mathrm{Rd}$, the mobile phase was (A) acetonitrile and (B) $0.05 \%$ phosphoric acid (aq) with a flow rate of $1.1 \mathrm{~mL} / \mathrm{min}$ as described below: 0 to $18 \mathrm{~min}, 21.5 \% \mathrm{~A} ; 18$ to $26 \mathrm{~min}, 21.5 \%$ to $28 \% \mathrm{~A} ; 26$ to $60 \mathrm{~min}, 28 \%$ to $34 \% \mathrm{~A} ; 60$ to 65 min, $34 \%$ to $21.5 \% \mathrm{~A}$; and 65 to $70 \mathrm{~min}, 21.5 \% \mathrm{~A}$ [33]. With respect to ginsenoside Rc, the flow gradient of the same two mobile phases was slightly modified as: 0 to $25 \mathrm{~min}, 19 \%$ to $20 \% \mathrm{~A} ; 25$ to 41 $\min , 20 \%$ to $29 \% \mathrm{~A} ; 41$ to $46 \mathrm{~min}, 29 \%$ to $32 \% \mathrm{~A} ; 46$ to $71 \mathrm{~min}, 32 \%$ to $34 \% \mathrm{~A} ; 71$ to $73 \mathrm{~min}, 34 \%$ to $19 \% \mathrm{~A}$; and 73 to $80 \mathrm{~min}, 19 \% \mathrm{~A}$. The eluent was detected using an ultraviolet detector at $203 \mathrm{~nm}$.

\subsection{Metabolic Effect of Fusarium spp. on the Concentrations of Ginsenoside}

To further investigate the direct effect of root pathogens on ginsenoside contents, $F$. solani or F. oxysporum mycelia were incubated in vitro with six ginsenosides $\left(\mathrm{Rg}_{1}, \mathrm{Re}, \mathrm{Rb}_{1}, \mathrm{Rc}, \mathrm{Rb}\right.$, and $\left.\mathrm{Rd}\right)$ on Czapek medium for up to 7 days and the contents of each ginsenoside in the culture medium were monitored using HPLC. To measure the effect of fungal infection on the stability of ginsenosides, fungal conidia of $F$. oxysporum and $F$. solani were incubated on ginsenoside-amended Czapek medium (2.0 $\mathrm{g} \mathrm{KNO}_{3}, 0.5 \mathrm{~g} \mathrm{KCl}_{1}, 1.0 \mathrm{~g} \mathrm{~K}_{2} \mathrm{HPO}_{3}, 0.5 \mathrm{~g} \mathrm{MgSO}_{4} \cdot 7 \mathrm{H}_{2} \mathrm{O}, 30.0$ g glucose in one liter distilled water). 
Specifically, $100 \mathrm{mg}$ of crude ginsenosides (Hongjiu Lit. Co., Ltd., Dalian, China) dissolved in $0.3 \mathrm{~mL}$ methanol was mixed with $2.7 \mathrm{~mL}$ Czapek solution in a 6-well tissue culture plate (Corning Incorporated, Ithaca, NY, USA). Conidia of the two Fusarium species were obtained by harvesting six-day-old cultures on PDA in $10 \mathrm{~mL}$ sterile distilled water. The concentration of conidia suspension was adjusted to $1 \times 10^{6}$ conidia/mL with a hemocytometer and $10 \mu \mathrm{L}$ was added to ginsenoside-amended Czapek medium. Sterile distilled water was added in place of fungal suspension as a control. The culture plates were then incubated at $25^{\circ} \mathrm{C}$ in the dark for seven days.

After seven days of incubation, mycelia were clipped out using tweezers, extensively wringed to release the culture solution, and washed in $0.5 \mathrm{~mL}$ distilled water three times. To recover the remaining ginsenosides, mixtures of spent culture solution and distilled water used in washing mycelia was extracted with water-saturated $n$ - $\mathrm{BuOH}(3 \mathrm{~mL})$ for five times. The combined $n$-BuOH phase was evaporated at $70{ }^{\circ} \mathrm{C}$. The dry residue was dissolved in $5 \mathrm{~mL} 50 \% \mathrm{MeOH}$ (aq) and filtered through a $0.45 \mu \mathrm{m}$ nylon membrane filter. The filtrated solution was stored at $4{ }^{\circ} \mathrm{C}$ for further HPLC analysis by using five ginsenosides $\mathrm{Rg}_{1}, \mathrm{Re}, \mathrm{Rb}_{1}, \mathrm{Rb}_{2}$, and $\mathrm{Rd}$ HPLC method as described above.

\subsection{Data Analysis}

Data were analyzed using statistical software SPSS (SPSS version 13.0; SPSS Inc., Chicago, IL, USA). Comparisons between the mean values of data of ginsenoside concentrations either in ginseng roots or in spent ginsenoside-amended Czapek medium were respectively performed using Fisher's least significant difference (LSD) test, at the significance level $\alpha=0.05$. A two-way analysis was performed among the ginsenoside contents data in three parts (I, II, III) of two tissue types (xylem, phloem) of healthy ginseng roots. A $p$ value $<0.05$ indicates a significant difference.

\section{Conclusions}

We have found that both Fusarium solani and F. oxysporum affected the productions of ginsenosides in the infected roots of American ginseng, and ginsenoside changes occurred wherever Fusarium spp. reached or was present in the infected phloem tissue. Fungal biodegradation might be one of the reasons for the observed ginsenoside level alterations. The biology and biochemistry in uninfected root tissues did not change. It is unclear how saprophytic bacteria affect ginsenosides under natural conditions after root pathogen infection. This study provides a chemical basis for the response of American ginseng root to Fusarium pathogens, and also gives new insights for quality control of traditional Chinese medicinal plants.

\section{Acknowledgments}

We thank Yong Luo, University of California-Davis, Kearney Agricultural Research and Extension Center, for his comments and editorial efforts on the manuscript prior to submission. This work is partially supported by the National Natural Science Foundations of China, grant number 81274071 and 30873380 . 


\section{Author Contributions}

X.L. and W.G. conceived and designed the experiments; X.J., A.J.C., and Y.L. performed the experiments; X.J., X.L., and J.J.H. analyzed the data and prepared the manuscript. All authors discussed, edited and approved the final manuscript.

\section{Conflicts of Interest}

The authors declare no conflict of interest.

\section{References}

1. Li, F.Y. The origin and classification of Chinese ginseng and American ginseng. In Chinese Ginseng and American Ginseng, 1st ed.; China Agricultural Scientech Press: Beijing, China, 2002; pp. 1-20.

2. Attele, A.S.; Wu, J.A.; Yuan, C.S. Ginseng pharmacology: Multiple constituents and multiple actions. Biochem. Pharmacol. 1999, 58, 1685-1693.

3. Leung, K.W.; Wong, A.S. Pharmacology of ginsenosides: A literature review. Chin. Med. 2010, 5, $20-26$.

4. Liu, M.; Zhang, J. Effects of ginsenoside $\mathrm{Rb}_{1}$ and $\mathrm{Rg}_{1}$ on synaptosomal free calcium level, ATPase and calmodulin in rat hippocampus. Chin. Med. J. 1995, 108, 544-547.

5. Yokozawa, T.; Satoh, A.; Cho, E.J. Ginsenoside-Rd attenuates oxidative damage related to aging in senescence-accelerated mice. J. Pharm. Pharmacol. 2004, 56, 107-113.

6. Li, D.M.; Wang, F.X.; Yan, F.Q.; Sun, H.P. In vitro anti-infection of ginseng saponin $\mathrm{Rb}_{2}$. Chin. J. Nosocomiol. 2011, 21, 1284-1286.

7. Yuan, Z.Y.; Meng, Z.; Chai, Y.S.; Lan, J.Q.; Lei, F.; Li, H.Y.; Xing, D.M.; Li, H.Y.; Du, L.J. Ginsenoside $\mathrm{Rg}_{1}$ reduced the invasion of $S$. aureus into respiratory epithelial cells involving pro-inflammatory cytokines and glucocorticoid receptor. J. Chin. Pharm. Sci. 2011, 20, 266-274.

8. Chen, J.C.; Chen, L.D.; Tsauer, W.; Tsai, C.C.; Chen, B.C.; Chen, Y.J. Effects of ginsenoside Rb 2 and Rc on inferior human sperm motility in vitro. Am. J. Chin. Med. 2001, 29, 155-160.

9. Battinelli, L.; Mascellino, M.T.; Martino, M.C.; Lu, M.; Mazzanti, G. Antimicrobial activity of ginsenosides. Pham. Pharmacol. Commun. 1998, 4, 411-413.

10. Bi, W.; Chen, J.; Jiao, X.L.; Gao, W.W. Identification of the pathogens causing the root rot and their pathogenicity on American ginseng in Beijing. Plant Prot. 2011, 37, 135-138.

11. Punja, Z.K.; Wan, A.; Goswami, R.S.; Verma, N.; Rahman, M.; Barasubiye, T.; Seifert, K.A.; Lévesque, C.A. Diversity of Fusarium species associated with discolored ginseng roots in British Columbia. Can. J. Plant Pathol. 2007, 29, 340-353.

12. Rahman, M.; Punja, Z.K. Biochemistry of ginseng root tissues affected by rusty root symptoms. Plant Physiol. Biochem. 2005, 43, 1103-1114.

13. Reeleder, R.D. Rhexocercosporidium panacis sp. nov., a new anamorphic species causing rusted root of ginseng (Panax quinquefolius). Mycologia 2007, 99, 91-98.

14. Punja, Z.K. Fungal pathogens of American ginseng (Panax quinquefolium) in British Columbia. Can. J. Plant Pathol. 1997, 19, 301-306. 
15. Reeleder, R.D.; Bramm all, R.A. Pathogenicity of Pythium species, Cylindrocarpon destructans and Rhizoctonia solani to ginseng seedling in Ontario. Can. J. Plant Pathol. 1994, 16, 311-316.

16. Darmono, T.W.; Owen, M.L.; Parke, J.L. Isolation and pathogenicity of Phytophthora cactorum from forest and ginseng garden soils in Wisconsin. Plant Dis. 1991, 75, 610-612.

17. Gao, W.W.; Jiao, X.L.; Bi, W.; He, C.N. The variation of ginsenosides in the infected roots of American ginseng (Panax quinquefolium). China J. Chin. Mat. Med. 2008, 33, 48-51.

18. Turner, E.M. The nature of the resistance of oats to the take-all fungus. J. Exp. Bot. 1953, 11, 403-412.

19. Bernards, M.A.; Yousef, L.F.; Nicol, R.W. The allelopathic potential of ginsenosides. In Allelochemicals: Biological Control of Plant Pathogens and Diseases, 1st ed.; Inderjit; Mukerji, K.G., Eds.; Springer Press: Dordrecht, The Netherlands, 2006; pp. 157-175.

20. Nicol, R.W.; Traquair, J.A.; Bernards, M.A. Ginsenosides as host resistance factors in American ginseng (Panax quinquefolius). Can. J. Bot. 2002, 80, 557-562.

21. Jiao, X.L.; Bi, W.; Li, M.; Luo, Y.; Gao, W.W. Dynamic response of ginsenosides in American ginseng. Plant Soil 2011, 339, 317-327.

22. Bais, P.H.; Prithiviraj, B.; Jha, K.A.; Ausubel, M.F.; Vivanco, M.J. Mediation of pathogen resistance by exudation of antimicrobials from roots. Nature 2005, 434, 217-221.

23. Glazebrook, J.; Ausubel, F.M. Isolation of phytoalexin-deficient mutants of Arabidopsis thaliana and characterization of their interactions with bacterial pathogens. PNAS 1994, 91, 8955-8959.

24. Toyomasu, T.; Kagahara, T.; Okada, K.; Koga, J.; Hasegawa, M.; Mitsuhashi, W.; Sassa, T.; Yamane, H. Diterpene phytoalexins are biosynthesized in and exuded from the roots of rice seedlings. Biosci. Biotechnol. Biochem. 2008, 72, 562-567.

25. Zhao, X.S.; Gao, J.; Song, C.C.; Fang, Q.; Wang, N.; Zhao, T.J.; Liu, D.B.; Zhou, Y.F. Fungal sensitivity to and enzymatic deglycosylation of ginsenosides. Phytochemistry 2012, 78, 65-71.

26. Goswami, R.S.; Punja, Z.K. Molecular and biochemical characterization of defense responses in ginseng (Panax quinquefolius) roots challenged with Fusarium equiseti. Physiol. Mol. Plant Pathol. 2008, 72, 10-20.

27. Yousef, L.F.; Bernards, M.A. In vitro metabolism of ginsenosides by the ginseng root pathogen Pythium irregulare. Phytochemistry 2006, 67, 1740-1749.

28. Zhao, X.S.; Wang, J.; Li, J.; Fu, L.; Gao, J.; Du, X.L.; Bi, H.T.; Zhou, Y.F.; Tai, G.H. Highly selective biotransformation of ginsenoside $\mathrm{Rb}_{1}$ to $\mathrm{Rd}$ by the phytopathogenic fungus Cladosporium fulvum (syn. Fulvia fulva). J. Ind. Microbiol. Biotechnol. 2009, 36, 721-726.

29. Fäldt, J.; Solheim, H.; Långström, B.; Borg-karlson, A.K. Influence of fungal infection and wounding on contents and enantiomeric compositions of monoterpenes in phloem of Pinus sylvestris. J. Chem. Ecol. 2006, 32, 1779-1795.

30. Guo, L.D.; Hyde, K.D.; Liew, E.C.Y. Identification of endophytic fungi from Livistona chinensis based on morphology and rDNA sequences. New Phytol. 2000, 147, 617-630.

31. Van Burik, J.A.; Schreckhise, R.W.; White, T.C.; Bowden, R.A.; Myerson, D. Comparison of six extraction techniques for isolation of DNA from filamentous fungi. Med. Mycol. 1998, 36, 299-303. 
32. Mirete, S.; Vazquez, C.; Mule, G.; Jurado, M.; Gonzalez-jaen, M.T. Differentiation of Fusarium verticillioides from banana fruits by IGS and EF-1 $\alpha$ sequence analyses. Eur. J. Plant Pathol. 2004, 110, 515-523.

33. Li, T.S.C.; Mazza, G.; Cottrell, A.C.; Gao, L. Ginsenosides in roots and leaves of American ginseng. J. Agric. Food Chem. 1996, 44, 717-720.

Sample Availability: Samples of the compounds ginsenoside $\mathrm{Rb}_{1}, \mathrm{R} \mathrm{b}_{2}, \mathrm{Rc}, \mathrm{Rd}, \mathrm{Re}$, and $\mathrm{Rg}_{1}$ are available from the authors.

(C) 2015 by the authors; licensee MDPI, Basel, Switzerland. This article is an open access article distributed under the terms and conditions of the Creative Commons Attribution license (http://creativecommons.org/licenses/by/4.0/). 